\title{
BMJ Open Benefit-risk assessment of HMG-CoA reductase inhibitors (statins): a discrete choice experiment
}

\author{
Tanatape Wanishayakorn, ${ }^{1}$ Korn Sornlertlumvanich, ${ }^{1}$ Surachat Ngorsuraches ${ }^{1,2}$
}

To cite: Wanishayakorn T, Sornlertlumvanich K, Ngorsuraches S. Benefit-risk assessment of HMG-CoA reductase inhibitors (statins): a discrete choice experiment. BMJ Open 2016;6:e009387. doi:10.1136/bmjopen-2015009387

- Prepublication history and additional material is available. To view please visit the journal (http://dx.doi.org/ 10.1136/bmjopen-2015009387).

Received 14 July 2015 Revised 22 December 2015 Accepted 18 January 2016

CrossMark

\footnotetext{
${ }^{1}$ Department of Pharmacy Administration, Faculty of Pharmaceutical Sciences, Prince of Songkla University, Hatyai, Songkhla, Thailand 2Department of Pharmacy Practice, College of Pharmacy, South Dakota State University, Brookings, South Dakota, USA

\section{Correspondence to} Dr Tanatape Wanishayakorn; Wanishayakorn.T@outlook. co.th
}

\section{ABSTRACT}

Objectives: To conduct the benefit-risk assessment of 3-hydroxy-3-methyl-glutaryl (HMG) coenzyme A reductase inhibitors (statins) using a discrete choice experiment, based on 3 major stakeholders' perspectives including patients, experts and policymakers in Thailand.

Design: A discrete choice experiment questionnaire survey in three stakeholders' perspectives.

Setting: Public hospitals in Thailand.

Participants: A total of 353 policymakers, experts and patients.

Outcomes: Stakeholders' preferences for assessment criteria (stroke reduction, myocardial infarction reduction, myalgia and hepatotoxicity). Statins' ranking and maximum acceptable risk in all perspectives were also calculated.

Results: For any perspective, the most and least important criteria were the risk of hepatotoxicity and the benefit of myocardial infarction reduction, respectively. Patients and experts agreed on the order of importance for myalgia and stroke reduction, but policymakers had different order of importance in these criteria. Overall, results showed that the highest and lowest chances of being chosen were atorvastatin and rosuvastatin, respectively. Only patients' ranking order was different from others. Maximum acceptable risk of hepatotoxicity was lower than that of myalgia, reflecting the greater concern of all perspectives to statin consequence on liver.

Conclusions: The results of benefit-risk assessment from every perspective were somewhat consistent. This study demonstrated the feasibility of applying a discrete choice experiment in the benefit-risk assessment of drugs and encouraged the engagement of multiple stakeholders in the decision-making process.

\section{INTRODUCTION}

Among healthcare interventions, drugs play important roles in curing and preventing diseases. More than 25000 drugs were registered in Thailand and approximately US $\$ 3057$ million were spent per year for imported and locally manufactured drugs. ${ }^{1}$ More drugs mean more complexity and require resources

\section{Strengths and limitations of this study}

- To the best of our knowledge, this is the only study that examined patients', clinicians' and policymakers' perspectives on the benefit-risk assessment (BRA) of drugs by applying the discrete choice experiment method, which can be a good example for various countries.

- This study focused only on the clinical benefits and risks of drugs because the aim is to provide an example of adopting a type of systematic BRA to the decision-making process. However, it is always possible to include more or different criteria.

- The participants in this study might not be representative of the overall Thai population because most of them, especially patients, resided in the southern part of Thailand. More data are needed to generalise the results.

to evaluate in drug approval and treatment selection because an improper decision would eventually impact people in various forms including adverse drug reactions (ADRs), toxicities and economic burdens. For instance, the costs of ADRs, requiring hospitalisations per case of ADRs in 2013, ranged from US $\$ 180$ to US $\$ 7038$ in Thailand. ${ }^{2}$

Nationally, there are two major drug assessments in Thailand: drug registration and drug selection to the National List of Essential Medicines (NLEM). In the registration process, the Thai Food and Drug Administration (FDA) evaluates drugs on the basis of their efficacies and safeties ${ }^{3}$ and would approve them if they have good efficacy and safety profiles. However, only certain approved drugs are listed in the NLEM since it is used for rational drug use and reimbursement purpose. In the drug selection process, the NLEM committee uses an ISafE score, which is a tool for grading each drug from four dimensions, including information, safety, compliance and efficacy, to aid their decision-making. ${ }^{4}$ Drugs with 
more benefits and less risks would be more potentially listed.

Even though the ISafE score has been used for more than a decade in this process, there are some criticisms. First, the efficacy and safety scores are calculated from a few tertiary information sources, including Micromedex DRUGDEX, Medscape Druginfo, Micromedex Drug Interaction Database, and Clinical Pharmacology CD-ROM. ${ }^{4}$ It could be difficult for new drugs to get high scores since their available information is usually limited. Second, every dimension of the ISafE score is treated with equal importance and it may not be always appropriate in real-world cases. In addition, the process has not included various stakeholder, especially patient, perspectives to make a comprehensive judgement. ${ }^{5}$ Specifically, the assessments are mostly based on the policymakers' perspective at the national level, which may be different from other stakeholders' perspectives. From these reasons, this drug assessment process could be improved and was the focus of this study.

The US FDA and European Medicines Agency (EMA) suggested a systematic benefit-risk assessment (BRA) in the drug assessment process. ${ }^{6}{ }^{7}$ BRA is the drug evaluation concept, which systematically focuses on benefits and risks of drugs. There are several BRA methods, including multicriteria decision analysis (MCDA) and maximum acceptable risk (MAR), using a discrete choice experiment (DCE), which have grown rapidly in the healthcare literature due to their strong theoretical grounds and features. Therefore, a study was designed to apply both methods for the BRA of drugs in Thailand. This article is the MAR using the DCE part of the study.

Owing to limited resources, only 3-hydroxy-3-methyl-glutaryl (HMG) coenzyme A reductase inhibitors (statins) were chosen as a case study. There were various supporting reasons for choosing statins. First, statins have been widely used for reducing the level of plasma low-density lipoprotein cholesterol, which is an important target for cardiovascular risk management in coronary heart disease. Second, choices for selection were available since there were several statins-atorvastatin, fluvastatin, lovastatin, pravastatin, rosuvastatin and simvastatin-with different efficacies, health risks and prices in the Thai healthcare market. Another reason was that they were a member in the high-expenditure drug groups in Thailand. ${ }^{8}$ IMS Health Thailand reported that statins alone cost the country approximately US $\$ 154$ million or accounted for $5 \%$ of total drug expenditure in $2008 .{ }^{9}$ Specifically, the objective of this study was to quantify the benefits and risks of statins by using DCE, based on perspectives of patients, clinical experts and policymakers. The results from the application of this method could be used as an initial step for improving the drug selection process.

\section{METHODS}

DCE is one of the recommended methods for the BRA of drugs because of its ability to quantify the importance of each drug criterion and ability to measure the tradeoffs among those criteria. ${ }^{7}{ }^{10}$ It was used to measure the preferences of respondents for various treatment alternatives from well-designed choice sets. ${ }^{11}$ Each choice set contains various alternatives. Each alternative is composed of the same assessment criteria with different levels. Respondents are asked to choose among alternatives and/or no treatment (opt-out) option in each choice set. On the basis of the Random Utility Theory, DCE uses these decision data to estimate the trade-offs, which respondents are willing to make between alternative criteria, and which results in assigning relative weights to those criteria. ${ }^{12}$ In this study, the benefit and risk attributes of statins were used as drug criteria in DCE and their relative weights were used for quantifying the maximum risk of drugs that respondents were willing to accept in exchange for increasing drug efficacy. ${ }^{13}$ In order to increase validity of the study design and results, the study closely followed two DCE guidelines. $^{14} 15$

\section{Criteria and level identification}

To identify the assessment criteria of statins, interviews were separately conducted in policymakers, clinical experts and patients. The policymaker group comprised physicians and pharmacists, who were members of the Pharmacy and Therapeutic Committee (PTC) and experienced the process of drug selection in secondary or tertiary care public hospitals in Songkhla Province. Physicians and pharmacists, who took care of patients using statins at those hospitals, were in the expert group. The patient group comprised those patients who experienced use of any statin for $>6$ months in order to ensure their knowledge and experiences of statins. In-depth and focus group interviews were used with the policymaker and expert groups, and patient groups (5 patients each), respectively. After six individual interviews in both the policymaker and expert groups and three patient focus groups were conducted, data were saturated. The data were transcribed and analysed along with statin literature $^{16-22}$ and a previous DCE study. ${ }^{8}$ The benefit and risk criteria were chosen on the basis of their relevance, understandability and applicability, and they needed to be mutually exclusive. ${ }^{23}$ The chosen criteria included stroke reduction, myocardial infarction (MI) reduction, myalgia and hepatotoxicity. The drug interaction was frequently mentioned as an important criterion, but this study intended to include only direct harms from each statin. The think-aloud technique with three patients was used to test patients' understanding of these criteria. From studies of previous statins, the clinical parameters of four chosen criteria of six statins were gathered from minimum to maximum possible levels to represent and cover the characteristics of statins. In each criterion parameter, the lowest and highest levels were selected and ensured to contain these minimum and maximum clinical parameters. The levels between the lowest and highest levels in each criterion were then selected by 
spacing evenly. The descriptions of criteria and levels used in this study are in table 1.

\section{Questionnaire development}

From chosen criteria and levels, there were 108 possible alternatives $(4 \times 3 \times 3 \times 3)$ and it was not feasible to include all of them in a questionnaire. An orthogonal design (a fractional factorial design) was used to randomly draw a subset of all combinations by Ngene software (V.1.1.1). Finally, 36 choice sets were generated and divided into six blocks by the software. All choice sets were checked to avoid the duplication of alternatives. Each questionnaire comprised six choice sets from each block. Therefore, there were six different questionnaire versions. Each choice set consisted of two unlabelled alternatives describing hypothetical statins and one opt-out alternative as illustrated in figure 1. The purpose of adding the opt-out alternative was to simulate the realworld situation in which participants did not have to choose any alternative if they were not satisfied. Another choice set, which contained a dominant alternative (highest benefits and lowest risks), was added to every questionnaire for a validity check. The questionnaire also included questions on respondents' characteristics, descriptions of all assessment criteria, and detailed instructions with an example showing how to choose an alternative in a choice set.

Three patients and three pharmacy faculty members were asked to check the content validity of the questionnaire. It was then piloted with only the patient group $(\mathrm{N}=30)$ due to the limited numbers of policymakers and experts that needed to be reserved for the main study. No major change was made.

\section{Data collection}

The questionnaires were purposively given to three groups of stakeholders who were not involved in the interview step. These participants randomly received different questionnaire versions, but the total number of

\begin{tabular}{|c|c|c|}
\hline Criteria & Definition & $\begin{array}{l}\text { Selected } \\
\text { levels (\%) }\end{array}$ \\
\hline Stroke & $\begin{array}{l}\text { Percentage of stroke event } \\
\text { reduction, compared with } \\
\text { placebo }\end{array}$ & $5,15,25,35$ \\
\hline MI & $\begin{array}{l}\text { Percentage of Ml event } \\
\text { reduction, compared with } \\
\text { placebo }\end{array}$ & $10,40,70$ \\
\hline Myalgia & $\begin{array}{l}\text { Percentage of myalgia } \\
\text { event, compared with } \\
\text { placebo }\end{array}$ & $0,15,30$ \\
\hline Hepatotoxicity & $\begin{array}{l}\text { Percentage of } \\
\text { hepatotoxicity event, } \\
\text { compared with placebo }\end{array}$ & $0,3,6$ \\
\hline
\end{tabular}

participants in each perspective per questionnaire version was similar at the end of the study.

While the policymaker group included physicians and pharmacists, who were PTC members at public hospitals or members of the NLEM cardiology and endocrinology working groups, the clinical expert group included those who had experience in statins use with patients. The patient group consisted of patients who continuously used statins for at least 3 months. Since the choice sets used in this study were unlabelled choices, there was no specific sample size calculation formula. ${ }^{24}$ By rule of thumb, the sample size should not be $<200$ in any perspective. ${ }^{25}$ Owing to the limited number of policymakers and clinical experts, the sample size of these two perspectives was adjusted to at least 60 participants, which was the sample size of healthcare practitioners used in previous studies. ${ }^{26-28}$ However, these sample sizes were only initially estimated. Data collection continued until all criteria became statistically significant, as a suggestion from previous literature for obtaining meaningful DCE results. ${ }^{29}$ The questionnaires were directly administered to all respondents and their oral consent was asked before they started. All questionnaires were collected immediately after they finished. Owing to the limited budget, only clinical experts and policymakers received US $\$ 5.6$ per person as incentive for their study participation.

\section{Data analysis}

Data from three stakeholder groups were separately analysed. The selected alternatives were coded as ' 1 ' and other alternatives were coded as ' 0 '. By using Nlogit, multinomial logit models were developed to estimate respondents' utility or preference models. According to McFadden's random utility theory, utility (U) of each individual ( $\mathrm{n}$ ) for alternative (i) could be described by each criterion as the equation shown below. ${ }^{30}$

$$
\mathrm{U}_{\mathrm{in}}=\mathrm{X}_{1 \mathrm{i}} \beta_{1 \mathrm{n}}+\mathrm{X}_{2 \mathrm{i}} \beta_{2 \mathrm{n}}+\mathrm{X}_{3 \mathrm{i}} \beta_{3 \mathrm{n}}+\mathrm{X}_{4 \mathrm{i}} \beta_{4 \mathrm{n}}+\varepsilon_{\mathrm{in}}
$$

where $\mathrm{X}_{1 \mathrm{i}}, \mathrm{X}_{2 \mathrm{i}}, \mathrm{X}_{3 \mathrm{i}}$ and $\mathrm{X}_{4 \mathrm{i}}$ were the levels of stroke, $\mathrm{MI}$, myalgia and hepatotoxicity in alternative (i), respectively; $\beta_{1 \mathrm{n}}, \beta_{2 \mathrm{n}}, \beta_{3 \mathrm{n}}$ and $\beta_{4 \mathrm{n}}$ were the estimated coefficients of stroke, MI, myalgia and hepatotoxicity criteria of individual $(\mathrm{n})$, respectively; and $\varepsilon_{\text {in }}$ were error terms, which had independent identically distributed (IID) property and extreme value type $\mathrm{I}$ distribution. All $\mathrm{X}_{1 \mathrm{i}}, \mathrm{X}_{2 \mathrm{i}}, \mathrm{X}_{3 \mathrm{i}}$ and $\mathrm{X}_{4 \mathrm{i}}$ were continuous variables in this model. All models did not include any alternative specific constant since the alternatives used in this study were generic or they were unlabelled alternatives. ${ }^{31}$

The criterion coefficients reflected the preference of stakeholders for those four criteria and were used to calculate the probability of being chosen of each statin in each perspective. The probability of each statin being chosen in each statin was calculated by the ratio between the exponential utility of each statin and the summation of the exponential utilities in all statins. The utility of 
Figure 1 Choice set example.

MI, myocardial infarction.

\begin{tabular}{|c|c|c|c|}
\hline \multicolumn{4}{|c|}{ Choice set: $\mathbf{X}$} \\
\hline Criteria & Drug A & Drug B & \multirow{5}{*}{$\begin{array}{c}\text { Neither A } \\
\text { nor B }\end{array}$} \\
\hline Stroke & $\begin{array}{c}5 \% \text { stroke event reduction, } \\
\text { compared to placebo }\end{array}$ & $\begin{array}{c}15 \% \text { stroke event reduction } \\
\text { compared to placebo }\end{array}$ & \\
\hline MI & $\begin{array}{l}70 \% \text { Ml event reduction, } \\
\text { compared to placebo }\end{array}$ & $\begin{array}{l}10 \% \text { Ml event reduction, } \\
\text { compared to placebo }\end{array}$ & \\
\hline Myalgia & 30 in 100 patients & None of myalgia event & \\
\hline Hepatotoxicity & 3 in 100 patients & 3 in 100 patients & \\
\hline $\begin{array}{l}\text { Please mark an } \\
\text { "X" in the box } \\
\text { you choose }\end{array}$ & A & B & $\begin{array}{c}\text { Neither A } \\
\text { nor B }\end{array}$ \\
\hline
\end{tabular}

ratios between benefit and risk coefficients. The MAR results from all perspectives were used to measure acceptable risk level in each statin by multiplying the performance benefit level of each statin with MAR each benefit criterion related to. The comparisons between estimated risk levels and actual statin risk levels were made after the calculation to demonstrate the acceptable statins, which had their myalgia and hepatotoxicity levels lower than the MAR levels in each perspective.

\section{RESULTS}

\section{Participants' characteristics}

The questionnaires were collected from 63 experts, 67 policymakers and 240 patients. In the patient group, only 223 questionnaires were used in the analyses because 17 patients chose the wrong alternative in the choice set for validity check. The characteristics of stakeholders are shown in table 2. Most of the participants in each group were women $(50.7-66.7 \%)$. The average age was 51.2 years for patients, 32.9 years for experts and 41.5 years for policymakers. In the patient group, $89.7 \%$ of patients had an education background lower than a bachelor's degree, $71 \%$ had comorbidity, and $70 \%$ were covered by universal coverage health insurance scheme. The percentages of physicians in expert and policymaker groups were $49 \%$ and $60 \%$, respectively. For the expert group, the average working year in their specialties was 6.1 years. For the policymaker group, the numbers of year that they were the members of PTC and NLEM committee were on average 9.3 and 7.9 years, respectively.

\section{Stakeholders' preferences and ranking}

All estimated coefficients, as described in table 3, were in line with the meanings of benefit and risk. Preferences for benefit and risk criteria increased and decreased when their levels were raised by $1 \%$, respectively. All coefficients were statistically significant $(\mathrm{p}<0.001)$ and all prediction models fitted well with the data (McFadden's $\mathrm{R}^{2}$ of $0.176,0.286$ and 0.284 for patient, expert and policymaker models, respectively). While hepatotoxicity was the most important criterion, MI was the least important criterion from all 
Table 2 Participants' characteristics

\begin{tabular}{|c|c|}
\hline Age, years, mean (SD) & $51.2(0.8)$ \\
\hline Female, $\mathrm{N}(\%)$ & $137(61.4)$ \\
\hline $\begin{array}{l}\text { Education level: lower than Bachelor's } \\
\text { degree, } \mathrm{N}(\%)\end{array}$ & $200(89.7)$ \\
\hline Had a history of vascular disease, N (\%) & $24(10.8)$ \\
\hline Monthly income, US\$, mean (SD) & $470.6(29.8)$ \\
\hline \multicolumn{2}{|l|}{ Comorbidities, N (\%) } \\
\hline Hypertension & $54(24.2)$ \\
\hline Diabetes mellitus & $47(21.1)$ \\
\hline Others & $59(26.4)$ \\
\hline \multicolumn{2}{|l|}{ Health plan, $\mathrm{N}(\%)$} \\
\hline Universal coverage & $156(70)$ \\
\hline Others & $67(30)$ \\
\hline Duration of treatment, years, mean (SD) & $3.15(0.3)$ \\
\hline \multicolumn{2}{|c|}{ Experienced adverse events from statins, $\mathrm{N}(\%)$ : } \\
\hline Myalgia & $4(1.8)$ \\
\hline Rash & $2(0.9)$ \\
\hline \multicolumn{2}{|l|}{ Clinical experts $(\mathrm{N}=63)$} \\
\hline Age, years, mean (SD) & $32.9(0.7)$ \\
\hline Female, N (\%) & $42(67)$ \\
\hline Experience in specialties, years, mean (SD) & $6.1(0.6)$ \\
\hline \multicolumn{2}{|l|}{ Hospital level, N (\%) } \\
\hline Community & $24(38)$ \\
\hline Provincial & $27(43)$ \\
\hline Regional & $12(19)$ \\
\hline \multicolumn{2}{|l|}{ Policymakers ( $N=67)$} \\
\hline Age, years, mean (SD) & $41.4(1.2)$ \\
\hline Female, N (\%) & $34(51)$ \\
\hline $\begin{array}{l}\text { Experience in PTC }(\mathrm{N}=59) \text {, years, mean } \\
\text { (SD) }\end{array}$ & $9.3(0.9)$ \\
\hline \multicolumn{2}{|l|}{ Hospital level, N (\%) } \\
\hline Community & $25(43)$ \\
\hline Provincial & $26(44)$ \\
\hline Regional & $8(13)$ \\
\hline $\begin{array}{l}\text { Experiences in working groups for NLEM } \\
(\mathrm{N}=8) \text {, years, mean (SD) }\end{array}$ & $7.9(3.4)$ \\
\hline \multicolumn{2}{|l|}{ Working group category, N (\%) } \\
\hline Cardiology & $6(75)$ \\
\hline Endocrinology & $2(25)$ \\
\hline
\end{tabular}

NLEM, National List of Essential Medicines; PTC, Pharmacy and Therapeutic Committee. criterion's coefficient was varied, the most sensitive criterion was MI prevention in most statins being chosen, except rosuvastatin, which was mostly affected by stroke prevention in any perspective and pravastatin in only the expert's perspective. Overall, the coefficients of risk criteria made relatively minor changes. For the criterialevel part, varying MI prevention level had the most impact on probability of being chosen in most statins, except atorvastatin, fluvastatin and rosuvastatin in the patient's perspective, in which hepatotoxicity level had the most impact. In the patient's perspective, myalgia level had the least impact on pravastatin and rosuvastatin, while stroke level had the least effect on other statins. In the expert's perspective, stroke prevention level had the least impact on atorvastatin and lovastatin, while myalgia level had the least effect on other statins. In the policymaker's view, myalgia level had the least impact on all statins.

\section{Maximum acceptable risk}

The MAR levels in myalgia and hepatotoxicity, which stakeholders were willing to accept in order to trade for $1 \%$ incremental level in reducing stroke or MI events, are shown in table 5. For every perspective, the MAR of hepatotoxicity ranged from 0.084 to 0.135 and from 0.067 to 0.115 for stroke and MI reductions, respectively. These were lower than the MAR of myalgia that ranged from 0.633 to 1.123 for stroke reduction and from 0.502 to 0.965 for MI reduction. These reflected lower acceptances in having a higher chance of liver toxicity than chance of myalgia to trade off with higher benefit levels of either stroke or MI reductions. In other words, higher importance in stroke reduction was reflected by higher MAR because stakeholders would accept more risk for more benefit level in stroke reduction.

The MAR of each statin is presented in table 6 . Comparing between risk parameters of each statin and the maximum possible risk level in all perspectives, the levels of myalgia in every statin were acceptable because the myalgia level in each statin did not exceed the maximum possible risk level. While the levels of hepatotoxicity of fluvastatin, lovastatin and pravastatin exceeded the acceptance levels in some perspectives, the level of this criterion in rosuvastatin exceeded the acceptance levels in every perspective. On the basis of MAR results, only atorvastatin and simvastatin were therefore acceptable in all perspectives.

\section{DISCUSSION}

This study intended to assess the benefits and risks of statins, based on the perspectives of patients, experts and policymakers, by using DCE as a BRA tool. The study started with identifying the benefit and risk criteria of statins. Even though these criteria were available in an existing DCE study, ${ }^{8}$ they could not be directly applied to this study context owing to various reasons. For instance, the previous study included inputs from only 
Table 3 Estimated parameters of multinomial logit models

\begin{tabular}{|c|c|c|c|c|c|c|}
\hline \multirow[b]{2}{*}{ Criteria } & \multicolumn{2}{|c|}{ Patients ( $\mathrm{N}=223)$} & \multicolumn{2}{|c|}{ Clinical experts ( $\mathrm{N}=63)$} & \multicolumn{2}{|c|}{ Policymakers (N=67) } \\
\hline & Coefficient $^{\star}$ & SE & Coefficient* & SE & Coefficient $^{\star}$ & SE \\
\hline Stroke & 0.026 & 0.004 & 0.050 & 0.009 & 0.049 & 0.009 \\
\hline $\mathrm{Ml}$ & 0.021 & 0.002 & 0.037 & 0.004 & 0.042 & 0.004 \\
\hline Myalgia & -0.041 & 0.004 & -0.061 & 0.008 & -0.044 & 0.007 \\
\hline Hepatotoxicity & -0.308 & 0.020 & -0.367 & 0.043 & -0.368 & 0.041 \\
\hline$L-L_{0}$ & \multicolumn{2}{|c|}{-1426.439} & \multicolumn{2}{|c|}{-406.292} & \multicolumn{2}{|c|}{-433.501} \\
\hline Pseudo $R^{2} \dagger$ & \multicolumn{2}{|c|}{0.176} & \multicolumn{2}{|c|}{0.286} & \multicolumn{2}{|c|}{0.284} \\
\hline Number of observations $\ddagger$ & \multicolumn{2}{|c|}{4014} & \multicolumn{2}{|c|}{1134} & \multicolumn{2}{|c|}{1206} \\
\hline $\begin{array}{l}{ }^{*} \text { Coefficient with } p<0.001 \text {. } \\
\text { †McFadden's pseudo }{ }^{2} \text {. } \\
\text { †Numbers of observations for } \\
\text { L-L } L_{0} \text {, log-likelihood; MI, myoc }\end{array}$ & $\begin{array}{l}\text { akeholder gro } \\
\text { arction. }\end{array}$ & & & & & \\
\hline
\end{tabular}

experts and patients, and had no latest data on some statins. The participant interviews were used to confirm the inclusion of important criteria in those perspectives and to verify patients' understanding about terms in the benefits and risks of statins. However, the results showed that these criteria were consistent with those in the previous DCE study with minor changes in measuring units and definitions and they also aligned with those criteria in previous clinical studies of statins. ${ }^{16-22}$ This study used the same measuring unit for the levels of all attributes. It allowed the comparisons among the relative effects of all criteria on stakeholders' preferences. The study questionnaire included only important four benefit and risk criteria to minimise the cognitive burden on respondents. ${ }^{14}$ Similarly, the numbers of levels in each criterion were kept as simple as possible by selecting three to four levels in each criterion and they also allowed orthogonal design. ${ }^{33}$

The results from DCE demonstrated that every stakeholder group placed the highest emphasis on the hepatotoxicity risk of statins. Conversely, MI event reduction was the least important to them. These results were consistent with the previous studies' results. ${ }^{84}$ However, the results of other criteria varied across perspectives. The

Table 4 Probability of each statin being chosen and ranking, separated by perspective

\begin{tabular}{|c|c|c|c|}
\hline \multirow[b]{2}{*}{ Statins } & \multicolumn{3}{|c|}{$\begin{array}{l}\text { Probability of each statin being chosen } \\
\text { (ranking) }\end{array}$} \\
\hline & $\begin{array}{l}\text { Patients } \\
(\mathrm{N}=223)\end{array}$ & $\begin{array}{l}\text { Clinical } \\
\text { experts } \\
(\mathrm{N}=63)\end{array}$ & $\begin{array}{l}\text { Policymakers } \\
(\mathrm{N}=67)\end{array}$ \\
\hline Atorvastatin & $0.221(1)$ & $0.262(1)$ & $0.279(1)$ \\
\hline Fluvastatin & $0.156(4)$ & $0.173(3)$ & $0.185(3)$ \\
\hline Lovastatin & $0.160(3)$ & 0.160 (4) & $0.146(4)$ \\
\hline Pravastatin & $0.147(5)$ & $0.113(5)$ & $0.103(5)$ \\
\hline Rosuvastatin & $0.120(6)$ & 0.097 (6) & $0.098(6)$ \\
\hline Simvastatin & $0.196(2)$ & $0.196(2)$ & $0.190(2)$ \\
\hline
\end{tabular}

second important criterion was myalgia risk in the patient and expert groups, but it was stroke event reduction in the policymaker group. These results implied that patients and experts had more concerns on the harmful effects of drugs when they chose drugs from the same group. Previous DCE studies also tended to show that risks were more important than benefits. ${ }^{11} 3536$ One of the reasons could be that patients did not want any additional harm since they already suffered from an existing disease. Similarly, the experts had direct experiences with patients and they did not want to suffer any bad consequence from their treatment decisions. For patients, hepatotoxicity, especially as compared with myalgia, might also sound more life-threatening to them, which could lead to hospital admissions, work absences or losing incomes. On the other hand, one of the reasons for the different orders of importance across drug criteria in the policymaker group could be that they might base their decisions on broader views and they could only focus on major risks and benefits, which were hepatotoxicity and stroke reduction in this case. Interestingly, according to the participants' preferences, the results of probability of each statin being chosen showed the same ranks for the highest and lowest preferred statins, atorvastatin and rosuvastatin, respectively. The patient group disagreed with the expert and policymaker groups for only the ranks of fluvastatin and lovastatin.

The results from MAR reflected the lowest acceptance for trading off between raising risk and benefit among respondents. Intuitively, every stakeholder group would have a higher MAR level for myalgia than for hepatotoxicity. More interestingly, these results showed that the patient group had a lower MAR level for both myalgia and hepatotoxicity than the expert and policymaker groups did, regardless of stroke or MI event reductions. In other words, the patient group seemed to be more sensitive to the risks than the expert and policymaker groups. It was possible that they did not know how much those risks would affect them. On the other hand, since the expert and policymaker groups knew them, they 
Table 5 MAR for each risk criterion for $1 \%$ incremental benefit level, separated by perspective

\begin{tabular}{|c|c|c|c|c|}
\hline \multirow{3}{*}{ Perspective } & \multicolumn{4}{|c|}{ MAR level (\%) for $1 \%$ incremental benefit level } \\
\hline & \multicolumn{2}{|c|}{ Myalgia (\%) } & \multicolumn{2}{|c|}{ Hepatotoxicity (\%) } \\
\hline & Stroke & MI & Stroke & MI \\
\hline Patients $(\mathrm{N}=223)$ & 0.633 & 0.502 & 0.084 & 0.067 \\
\hline Clinical experts $(\mathrm{N}=63)$ & 0.808 & 0.608 & 0.135 & 0.102 \\
\hline Policymakers $(\mathrm{N}=67)$ & 1.123 & 0.965 & 0.134 & 0.115 \\
\hline
\end{tabular}

agreed on the level of MAR for hepatotoxicity when they needed to trade it off with stroke event reduction. Another lesson learnt from the study results was that the policymaker group tended to accept a higher level of MAR, as compared with the other two groups. This confirmed that the inclusion of the perspectives of patients or experts who directly provided cares for patients could improve the decision-making process since they might not be the same as the perspective of policymakers.

When MAR was applied to statins that were available in Thailand, there were only two acceptable statins, atorvastatin and simvastatin, in the patients' perspective. Even though lovastatin or fluvastatin has higher efficacy levels, patients rejected them because of their high-risk levels. These results were in line with the ranking results showing that atorvastatin and simvastatin were ranked the first and second, respectively. On the basis of the MAR results, the expert group could tolerate the risks of fluvastatin and pravastatin and accepted them in addition to atorvastatin and simvastatin. On the other hand, since the policymaker group tended to accept higher levels of MAR to trade for therapeutic effects, they could therefore accept almost every statin, except rosuvastatin. In their perspective, rosuvastatin had an unacceptable hepatotoxicity risk level, as relatively compared with its stroke prevention level. These results simply confirmed the importance of patient engagement to the healthcare decision-making process. Traditionally, patient engagement, especially at the drug selection level, has been negligible in Thailand since policymakers are doubtful about patients' knowledge and competency, and tend to believe that patients may try to persuade towards less-restricted or irrational decisions. The results of this study indicated that if patients were well informed about the benefits and risks of drugs, they could make similar or more conservative decisions.

Sensitivity analysis was conducted to examine the uncertainty of the parameters used in this study. Two

Table 6 MAR of each statin, separated by perspective

\begin{tabular}{|c|c|c|c|c|c|c|c|}
\hline \multicolumn{3}{|c|}{ Level of risk parameters of each statin ${ }^{19-22}$} & \multicolumn{5}{|c|}{ MAR of each statin for each benefit criterion } \\
\hline \multirow[t]{2}{*}{ Statins } & \multirow[t]{2}{*}{ Myalgia (\%) } & \multirow[t]{2}{*}{ Hepatotoxicity (\%) } & \multirow[t]{2}{*}{ Perspective } & \multicolumn{2}{|c|}{ Myalgia (\%) } & \multicolumn{2}{|c|}{ Hepatotoxicity (\%) } \\
\hline & & & & Stroke & MI & Stroke & MI \\
\hline \multirow{3}{*}{ Atorvastatin } & 5.60 & 1.25 & Patients* & 15.83 & 19.07 & 2.11 & 2.55 \\
\hline & & & Experts $\dagger$ & 20.21 & 23.12 & 3.38 & 3.87 \\
\hline & & & PM¥ & 28.09 & 36.69 & 3.34 & 4.37 \\
\hline \multirow[t]{3}{*}{ Fluvastatin } & 4.40 & 2.55 & Patients* & 13.30 & 21.58 & $1.78 \S$ & 2.88 \\
\hline & & & Experts $†$ & 16.97 & 26.16 & 2.84 & 4.38 \\
\hline & & & PM‡ & 23.59 & 41.52 & 2.81 & 4.94 \\
\hline \multirow[t]{3}{*}{ Lovastatin } & 2.40 & 1.90 & Patients* & 31.00 & 9.04 & 2.62 & $1.21 \S$ \\
\hline & & & Experts $\dagger$ & 25.06 & 10.95 & 4.19 & $1.83 \S$ \\
\hline & & & PM $\ddagger$ & 34.83 & 17.38 & 4.15 & 2.07 \\
\hline \multirow[t]{3}{*}{ Pravastatin } & 1.00 & 1.20 & Patients* & 8.86 & 11.04 & $1.18 \S$ & 1.47 \\
\hline & & & Experts $\dagger$ & 11.32 & 13.38 & 1.89 & 2.24 \\
\hline & & & PM $\ddagger$ & 15.73 & 21.24 & 1.87 & 2.53 \\
\hline \multirow[t]{3}{*}{ Rosuvastatin } & 2.80 & 2.20 & Patients ${ }^{*}$ & 6.33 & 18.07 & $0.85 \S$ & 2.41 \\
\hline & & & Experts $†$ & 8.08 & 21.90 & $1.35 \S$ & 3.66 \\
\hline & & & PM & 11.23 & 34.76 & $1.34 \S$ & 4.14 \\
\hline \multirow[t]{3}{*}{ Simvastatin } & 3.70 & 1.00 & Patients* & 15.20 & 13.05 & 2.03 & 1.74 \\
\hline & & & Experts $†$ & 19.40 & 15.82 & 3.24 & 2.65 \\
\hline & & & PM $\ddagger$ & 26.96 & 25.10 & 3.21 & 2.99 \\
\hline
\end{tabular}

*Patients $(\mathrm{N}=223)$.

†Clinical experts $(\mathrm{N}=63)$.

‡PMs (N=67).

§Unacceptable risk level.

MAR, maximum acceptable risk; MI, myocardial infarction; PM, policymaker. 
potential parameters, clinical parameters and estimated coefficients that could affect the results, were varied. The results showed that the uncertainty of clinical parameters had higher effects, while the effects from estimated coefficients were negligible. These confirmed that input data for the decision-making process are important and should be cautiously obtained. On the other hand, the uncertainty from DCE estimations, which might also include sample size and other statistical assumptions, should not be a reason for not adopting this type of BRA.

This study had limitations. First, while the study results showed the possibility of using DCE in BRA for the drug evaluation and selection process, DCE is a relatively new tool to the healthcare environment in Thailand. One of the major weaknesses is that it can include a certain number of drug criteria. It needs to coincide with participants' cognitions and/or their cognitive burdens to obtain valid results. Second, this study focused only on the BRA of clinical benefits and risks of drugs while there are other important criteria for drug evaluation and selection that were not included. For instance, other assessment criteria of the ISafE score include the route of administration and frequency or the economic evaluation of drugs includes the cost criterion. However, this study only intended to provide an example of adopting this type of systematic BRA to the decision-making process. It could be used as a supplemental tool since it allows more engagements from other stakeholders besides policymakers. Third, this study assumed the homogeneity of preference and independence of observed choices in the analyses. Although there were strict assumptions, they were widely used in DCE and the scope of this study was only to explore the application of DCE to the BRA context. Moreover, the test of heterogeneity requires a larger sample size, which was not possible for the expert and policymaker groups. Another limitation was that the participants in this study might not be representative of the overall Thai population because most of them, especially patients, resided in the southern part of Thailand. More data collection is needed to generalise the results.

\section{CONCLUSION}

This study intended to use DCE to assess the benefits and risks of statins, based on different stakeholders' perspectives, including patients, experts and policymakers. All stakeholders placed the most and least emphasis on the risk from hepatotoxicity and the benefit from MI prevention, respectively. The importance of myalgia and stroke prevention was weighted differently among the three perspectives. Patients tended to have the lowest acceptance of risk levels, which reflected their highest worries in risk criteria of statins. Atorvastatin and simvastatin were the two most preferred statins, which were consistent with the decisions made in the current NLEM in Thailand. The study demonstrated the feasibility of applying DCE in the BRA of drugs.
Contributors TW and SN are responsible for all processes in this study; designing the study, collecting data, analysing and interpreting data, drafting the manuscript and approving the final manuscript. KS helped with the drafting of the manuscript and approval of the final manuscript.

Funding This work was supported by the Health Insurance System Research Office (HISRO), Prince of Songkla University Graduate School, and Faculty of Pharmaceutical Sciences, Prince of Songkla University, Thailand.

Disclaimer The funding agreement ensured the authors' independence in designing the study, interpreting the data, and writing and publishing the report.

Competing interests All the authors had financial support from the Health Insurance System Research Office (HISRO), Prince of Songkla University Graduate School, and Faculty of Pharmaceutical Sciences, Prince of Songkla University, Thailand for the submitted work.

Ethics approval The ethic committees, Faculty of Pharmaceutical Sciences, Prince of Songkla University.

Provenance and peer review Not commissioned; externally peer reviewed.

Data sharing statement No additional data are available.

Open Access This is an Open Access article distributed in accordance with the Creative Commons Attribution Non Commercial (CC BY-NC 4.0) license, which permits others to distribute, remix, adapt, build upon this work noncommercially, and license their derivative works on different terms, provided the original work is properly cited and the use is non-commercial. See: http:// creativecommons.org/licenses/by-nc/4.0/

\section{REFERENCES}

1. Bureau of drug control, Thailand's Food and Drug Administration (FDA). The cost of manufactured and imported drugs in Thailand from 1987 to 2012. http://drug.fda.moph.go.th/zone_search/files/ sea001_001.asp (accessed 23 Oct 2015).

2. Siltharm $C$, Thavorncharoensap $M$. Cost of adverse drug reactions (ADRs) induced hospitalization: a systematic review. Mahidol Univ J Pharm Sci 2013;40:40-9.

3. Ngorsuraches S, Meng W, Kim BY, et al. Drug reimbursement decision-making in Thailand, China, and South Korea. Value Health 2012;15(Suppl 1):S120-5.

4. Chongtrakul P, Sumpradit N, Yoongthong W. ISafE and the evidence-based approach for essential medicines selection in Thailand. Essent Drugs Monit 2005;34:18-19.

5. Egbrink MO. Patient involvement in benefit-risk assessment at the European Medicines Agency: a patient-informed analysis to determine the room for improvement by using quantitative patient preferences [master's thesis]. Netherland: University of Twente, Faculty of Behavioural, Management \& Social Sciences, 2013.

6. Maruthur NM, Joy S, Dolan J, et al. Systematic assessment of benefits and risks: study protocol for a multi-criteria decision analysis using the Analytic Hierarchy Process for comparative effectiveness research. F1000Res 2013;2:160.

7. European Medicines Agency. Benefit-risk methodology project: Work Package 2 Report: Applicability of current tools and processes for regulatory benefit-risk assessment. http://www.ema.europa.eu/docs/ en_GB/document_library/Report/2010/10/WC500097750.pdf (accessed 25 Oct 2015).

8. Ngorsuraches $\mathrm{S}$, Paannahrungsee $\mathrm{P}$, Wanishayakorn T. Civil servant medical beneficiaries' preference and willingness-to-pay for medications: a case study of HMG-CoA reductase inhibitors (statins) http://kb.hsri.or.th/dspace/handle/11228/3762 (accessed 25 Oct 2015).

9. Intercontinental Marketing Services. Thailand Healthcare Index Report 2008, IMS Health Thailand: Bangkok, 2009.

10. Guo JJ, Pandey S, Doyle J, et al. A review of quantitative risk-benefit methodologies for assessing drug safety and efficacyreport of the ISPOR Risk-Benefit Management Working Group. Value Health 2010;13:657-66.

11. Hauber AB, Arden NK, Mohamed AF, et al. A discrete-choice experiment of United Kingdom patients' willingness to risk adverse events for improved function and pain control in osteoarthritis. Osteoarthritis Cartilage 2013;221:289-97.

12. Hiligsmann M, Dellaert BG, Dirksen CD, et al. Patients' preferences for osteoporosis drug treatment: a discrete-choice experiment. Arthritis Res Ther 2014;16:R36. 
13. Johnson FR, Hauber AB, Ozdemir S, et al. Quantifying women's stated benefit-risk trade-off preferences for IBS treatment outcomes. Value Health 2010;13:418-23.

14. Lancsar E, Louviere J. Conducting discrete choice experiments to inform healthcare decision making: a user's guide. Pharmacoeconomics 2008;26:661-77.

15. Bridges JF, Hauber AB, Marshall D, et al. Conjoint analysis applications in health-a checklist: a report of the ISPOR Good Research Practices for Conjoint Analysis Task Force. Value Health 2011:14:403-13.

16. Ward S, Lloyd Jones M, Pandor A, et al. A systematic review and economic evaluation of statins for the prevention of coronary events. Health Technol Assess 2007:11:17-64.

17. Naci H, Brugts JJ, Fleurence R, et al. Comparative benefits of statins in the primary and secondary prevention of major coronary events and all-cause mortality: a network meta-analysis of placebocontrolled and active-comparator trials. Eur J Prev Cardiol 2013:20:641-57.

18. Naci H, Brugts JJ, Fleurence R, et al. Comparative effects of statins on major cerebrovascular events: a multiple-treatments meta-analysis of placebo-controlled and active-comparator trials. QJM 2013;106:299-306.

19. Kashani A, Phillips CO, Foody JM, et al. Risks associated with statin therapy: a systematic overview of randomized clinical trials. Circulation 2006;114:2788-97.

20. DRUGDEX® System [database on the Internet]. Greenwood Village, CO: Truven Health Analytics, 2013. http://www. micromedexsolutions.com (accessed 23 Oct 2015).

21. Novak KK, managing ed. Drug facts and comparisons. St. Louis, MO: Wolters Kluwer Health Inc., 2012:536-9.

22. Corbett AH, Dana WJ, Fuller MA, et al. Drug information handbook. 23rd edn. Hudson, OH: Lexi-Comp, Inc, 2014:191-1900.

23. Mussen F, Salek S, Walker S. A quantitative approach to benefit-risk assessment of medicines-part 1: the development of a new mode using multi-criteria decision analysis. Pharmacoepidemiol Drug Saf 2007;16(Suppl 1):S2-15

24. de Bekker-Grob EW, Hol L, Donkers B, et al. Labeled versus unlabeled discrete choice experiments in health economics: an application to colorectal cancer screening. Value Health 2010;13:315-23.
25. Orme BK. Getting started with conjoint analysis: strategies for product design and pricing research. 2nd edn. Madison, WI: Research Publishers LLC, 2010:57-66.

26. Davison SN, Kromm SK, Currie GR. Patient and health professional preferences for organ allocation and procurement, end-of-life care and organization of care for patients with chronic kidney disease using a discrete choice experiment. Nephrol Dial Transplant 2010;25: 2334-41.

27. Lee A, Gin T, Lau AS, et al. A comparison of patients' and health care professionals' preferences for symptoms during immediate postoperative recovery and the management of postoperative nausea and vomiting. Anesth Analg 2005;100:87-93.

28. Ubach C, Bate A, Ryan M, et al. Using discrete choice experiments to evaluate alternative electronic prescribing systems. Int J Pharm Pract 2002;10:191-200.

29. Rose JM, Bliemer MCJ. Sample size requirements for stated choice experiments. Transportation 2013;40:1021-41.

30. Louviere JJ, Flynn TN, Carson RT. Discrete choice experiments are not conjoint analysis. J Choice Model 2010;3:57-72.

31. Kjær T. A review of the discrete choice experiment - with emphasis on its application in health care. Health Economics Papers \#1, University of Southern Denmark, 2005

32. Youngkong S, Baltussen R, Tantivess $\mathrm{S}$, et al. Criteria for priority setting of HIV/AIDS interventions in Thailand: a discrete choice experiment. BMC Health Serv Res 2010;10:197.

33. Beelaerts van Blokland R. Designing stated choice experiments: an analysis of the effects of airport location on air passenger's travel choice. Delft: Delft University of Technology, 2008.

34. Johnson FR, Hauber AB, Gonzalez JM, et al. Patient preference weights for benefit-risk analysis: a statin case study. Poster session presented at: ISPOR 15th Annual International Meeting; 15-19 May 2010, Atlanta, GA.

35. Gonzalez JM, Johnson FR, Fairchild AO, et al. Patients at the center of regulatory decisions: using stated-preference data to help regulators answer difficult questions. Poster session presented at: ISPOR 16th Annual European Congress; 2-6 Nov 2013, Dublin, Ireland.

36. Arden NK, Hauber AB, Mohamed AF, et al. How do physicians weigh benefits and risks associated with treatments in patients with osteoarthritis in the United Kingdom? J Rheumatol 2012;39:1056-63. 